\title{
U.S. LIFE CYCLE INVENTORY DATABASE ROADMAP
}




\section{Vision Statement}

The U.S. Life Cycle Inventory Database will be the recognized source of U.S.-based, quality, transparent life cycle inventory data and will become an integral part of the rapidly expanding use of life cycle assessment as an essential environmental analysis and decision-making tool.

\section{Goals of the U.S. LCI Database Project}

- Maintain data quality and transparency.

- Cover commonly used materials, products, and processes in the United States with up-to-date, critically reviewed $\mathrm{LCl}$ data.

- Support the expanded use of LCA as an environmental decision-making tool.

- Maintain compatibility with international LCI databases.

- Provide exceptional data accessibility.

- Be fully and sustainably supported.

- Support U.S. industry competitiveness. 


\section{Executive Summary}

We make decisions concerning the environment every day, and many of these decisions are based on incomplete, inconsistent, and flawed information. Life cycle assessment (LCA) provides a holistic evaluation methodology and a consistent framework for making betterinformed decisions. Life cycle inventory (LCI) data are the primary inputs for conducting LCA studies. Studies based on high-quality data that are consistent, accurate, and relevant allow for robust, defensible, and meaningful results. The U.S. LCI Database (www.nrel.gov/ lci) was initiated in 2003 to fulfill the need for publicly available LCI data. The project has been well received; however, it needs to be further developed and expanded to meet evolving and growing demands. Recent meetings of interested parties have called for an increased effort to advance the database. A meeting of stakeholders on February 18, 2009, in Washington, D.C., and an on-line survey were used as inputs in the development of this roadmap.

Participants noted that LCA is being used as input for policy decisions, corporate management, product development, marketing, environmentally preferable purchasing programs, and carbon or greenhouse gas reporting. Other areas that are expected to see expansion include benchmarking for carbon trading, development of environmental product declarations, end-of-life analysis, and global trade analysis. We will also likely see LCA methods integrated with risk and social assessments, environmental externality studies, and geospatially focused impact assessments. The use of LCA, and thus the demand for LCI data, will likely continue to grow rapidly as we search for comprehensive answers to environmental issues.

We identified four critical paths:

- Project management

- Data management

- LCI data

- Communications.

Three main themes overlie these paths: the need for highquality, transparent data; expansion of the database; and international compatibility. This roadmap explores these themes and presents a detailed two-year action plan and long-range objectives to address these critical paths.

Success of this project depends heavily on strong partnerships with industry, government, LCA professionals, and academia. Communications will be essential to foster these partnerships, and this roadmap is an important part of the communications effort. 


\section{Introduction}

The drive toward sustainability and improved environmental decision-making is helping us recognize the value of validated data about the environmental outcomes of our actions. Life cycle assessment (LCA) provides a holistic, science-based analysis method for decision-makers in all sectors concerning policies, product purchases, process performance, and education systems. The use of LCA for product and service analysis is increasing and the demand for life cycle inventory (LCI) data is growing.

Quality LCAs require quality LCI data, which are not readily available. Often, LCA practitioners have to develop their own data or modify data from other countries for U.S. conditions. The assumptions and approaches used by different practitioners can lead to variable results. Having consistent U.S.-based data is essential if we are to understand and manage the environmental impacts of U.S.-based processes.

The U.S. LCI Database project began in 2001, when the U.S. Department of Energy (DOE) directed the National Renewable Energy Laboratory (NREL) and the Athena Institute to explore the development of a national public database. The U.S. LCI Database was created and has been publicly available at www. nrel.gov/lci since 2003. The project strives to provide publicly available LCI data following a consistent protocol, thus allowing users to objectively review and compare data based on similar data collection and analysis methods.

\section{What are we talking about?}

Life cycle assessment (LCA) is a holistic and systematic method for analyzing the environmental and human health impacts of a product or process across its life cycle. An LCA consists of four steps:

1. Define the goal and scope.

2. Analyze the inventory $(\mathrm{LCl})$.

3. Assess the impacts (LCIA).

4. Interpret the results.

Life cycle inventory ( $\mathrm{LCI}$ ) is the accounting method used to track the input and output material and energy flows associated with each step in a process or in the production of a product. An LCA of a cardboard box, for example, may involve linking dozens of $\mathrm{LCl}$ data sets to study the raw materials extraction, production, transportation, use, and recycling or disposal life cycle stages.

Life cycle impact assessment (LCIA) is the process of developing indicators of potential human and ecological impacts from the LCl data.
The advantages of such a data source include:

- It provides comprehensive information for policy makers to make consistent comparisons between policy options regarding environmental decisions.

- It enables better evaluation of environmental opportunities and trade-offs of alternative product systems.

- Indirect sources of environmental impacts can be addressed in the redesign of products for better overall environmental performance.

- Legitimate, verifiable environmental market claims can be better substantiated based on quality LCI data.

- Environmental hotspots can be identified and targeted for improvement.

- It provides input to measure and monetize environmental externalities through, for example, a cap-and-trade system.

Several recent events have called for a renewed support and expansion of the U.S. LCI Database. The Camp Long Declaration, ${ }^{1}$ drafted in October 2008, recognizes the growing demand for LCA and the need to support the U.S. LCI Database to become a comprehensive source of high-quality transparent data that are compatible with international standards. The National Science and Technology Council Committee on Technology called for "further development and maintenance of the U.S. LCI Database."2 On February 18, 2009, a stakeholders' meeting was held in Washington, D.C., to discuss the project and formulate a multi-year plan for expanding and refining the database. The plan represented in this document was developed with input from this meeting and from an on-line survey conducted prior to the meeting.

\footnotetext{
${ }^{1}$ www.lcacenter.org/pdf/CampLongDeclaration.pdf

${ }^{2}$ National Science and Technology Council Committee on Technology (2008). Federal Research and Development Agenda for Net-Zero Energy, High-Performance Green Buildings www.ostp.gov/galleries/NSTC Reports/ FederalRDAgendaforNetZeroEnergyHighPerformanceGreenBuildings.pdf
} 
Table 1. Critical Paths

\begin{tabular}{|c|c|c|c|}
\hline Project Management & Data Management & LCI Data & Communications \\
\hline $\begin{array}{l}\text { - Complete annual } \\
\text { operating plan. } \\
\text { - Establish advisory } \\
\text { boards. } \\
\text { - Develop a business plan. } \\
\text { - Partner with national and } \\
\text { international efforts. }\end{array}$ & $\begin{array}{l}\text { - Define a data quality } \\
\text { protocol. } \\
\text { - Revise data formats and } \\
\text { protocols. } \\
\text { - Complete database } \\
\text { updates. }\end{array}$ & $\begin{array}{l}\text { - Fill data gaps. } \\
\text { - Expand the database. } \\
\text { - Maintain current data. }\end{array}$ & $\begin{array}{l}\text { - Identify user needs. } \\
\text { - Develop a } \\
\text { communications plan. } \\
\text { - Update Web site and } \\
\text { project documents. }\end{array}$ \\
\hline
\end{tabular}

Defining where we want to be allows us to plan how to best get there. With this in mind, we asked database users to tell us the most important features of a public LCI Database, and we have compiled the following success factors for a viable database:

- Transparent, high-quality LCI data

- Comprehensive coverage of commonly used materials, products, and processes

- Up-to-date, relevant data

- International compatibility

- High data accessibility

- Complete database documentation

- Efficient data submission and validation methods

- Broad support and participation from government, industry, and academia

- Sustained financial viability.

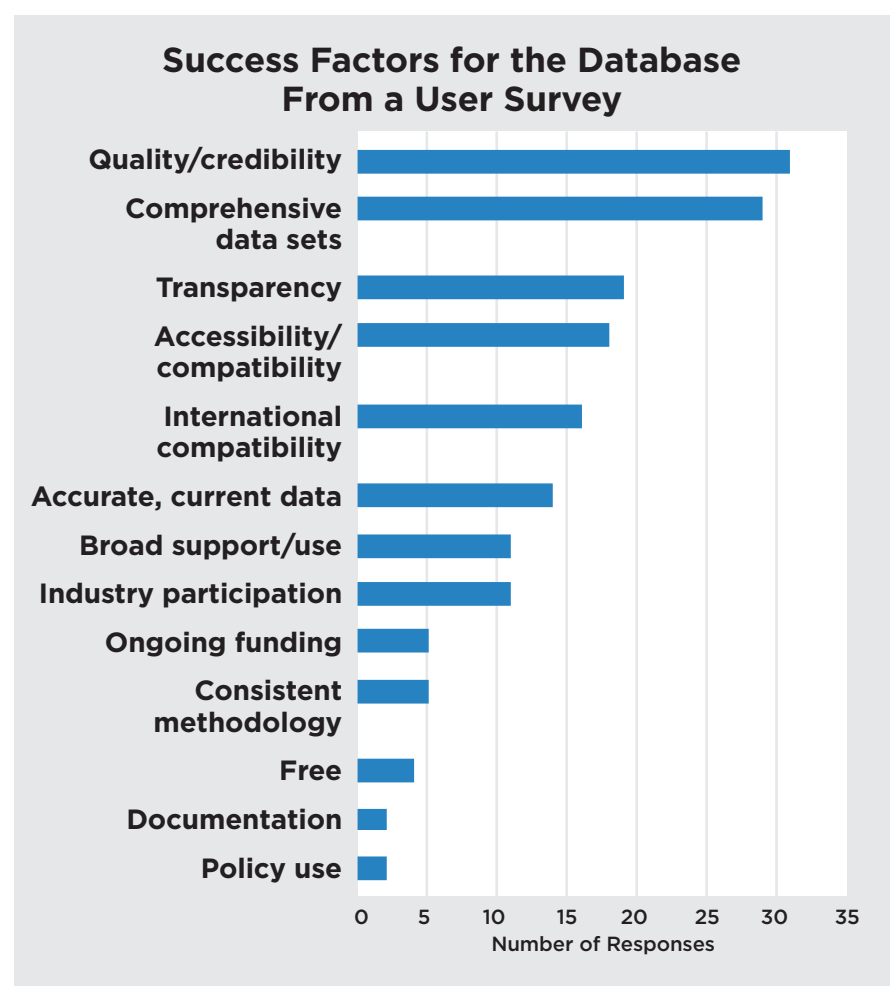

\section{Critical paths}

Realizing the vision for the database will require disciplined work and attention to critical paths for achieving our goals. We identified four critical paths with specific tasks for each path (see Table 1).

\section{How do we get there?}

The U.S. LCI Database has already made progress along many of these critical paths. A group of experts has been working to help guide the project. We are in contact with international LCA and LCI data experts, and we will increase our role in promoting international LCI data exchange. Data quality plans are in development and data gaps have been identified. The user survey and stakeholders' meeting in Washington, D.C., have helped identify user needs and provide input for this roadmap. Communications with stakeholders has been a central part of the project from the beginning and will continue to be vital to its success.

The next two years are seen as critical in advancing the U.S. LCI Database and promoting it to the appropriate level of quality and completeness. We have established an action plan for the next two years that addresses the critical paths and will propel the database project to the forefront of LCA in the United States. In addition, we have laid out a long-range map that will guide our plans. 
Compatibility with international LCI databases is an important success factor, and we will increase our collaboration with international groups to harmonize LCI data standards and promote data compatibility. This work is essential in light of growing global trade and global environmental issues.

\section{Data management}

Current database documents and tools will be reviewed, updated, and augmented to formulate an enhanced data management plan. Comprehensive and consistent data and database protocols that follow International Organization for Standardization requirements and are compatible with recognized international LCI efforts will form the foundation for the plan. Levels of data quality and data validation procedures will be defined in coordination with international experts. Items to be included in the data management plan are:

- Database functional, formatting, nomenclature, and documentation requirements

- Data quality control protocol

- Coordination with LCIA efforts

- Data publication and updating procedures

- Arbitration rules for settling disputes.

\section{Expansion/revision of the database}

Database expansion is a primary objective of the project and the subject of many user comments. We will explore several avenues for expanding the database. Many data are available in the United States today, but would need to be provided or purchased and then adapted to the U.S. LCI Database data format. In the immediate future, we will work with several groups to revise their data for inclusion in the U.S. LCI Database. Some data may be purchased and solicitations for these data and will be developed and sent out for proposals. Data priorities are based on initial database planning exercises, survey results, and the February 2009 stakeholders' meeting. (See Table 3.)

\section{Database development}

The current database contains LCI data for unit processes and some gate-to-gate processes. Users can browse through the data sets by category, view individual data sets online, and download single data sets or the entire database. New search-and-view applications will be added, which will be essential as the database grows. New applications will be explored
Table 3. Data Updates by Category

\begin{tabular}{|l|l|}
\hline Data Category & Action \\
\hline Energy and fuels & Update and expand \\
\hline Transportation & Update and expand \\
\hline Water & New \\
\hline Transformation processes & Expand \\
\hline Infrastructure & New \\
\hline Metals & Expand \\
\hline Paper and paper products & New \\
\hline Glass & New \\
\hline Plastics & Expand \\
\hline Chemicals and minerals & Expand \\
\hline Wood and wood products & Expand \\
\hline $\begin{array}{l}\text { Agricultural and biobased } \\
\text { products }\end{array}$ & Expand \\
\hline Packaging & New \\
\hline $\begin{array}{l}\text { Building products and } \\
\text { assemblies }\end{array}$ & New \\
\hline Textiles & New \\
\hline End of life & New \\
\hline
\end{tabular}

to improve data accessibility and usability. An application will be developed to streamline submission, review, and tracking of new data to the database.

\section{Communications}

An effective communications program is crucial to maintaining user and stakeholder support. Communications with users will ensure that the data are being used correctly and that we receive feedback about data quality and database usability. Partnerships between the database project managers, data suppliers, data users, end users, and supporters are critical for keeping the database up-to-date and relevant. Several communication avenues such as newsletters, Web site updates, user forums, educational materials, technical publications, conference presentations, conference calls, and Web meetings will be employed. 


\section{Long-Range Plan}

Maintaining the database as an up-to-date source of credible LCI data and achieving all the project goals will require a sustained effort. It will require support and input from several groups to keep the effort flourishing. Maintaining its long-term financial viability will be the biggest challenge and will require exploring alternative models and flexibility in operations. We have laid out several long-term objectives to guide the successful continuation of the database (see Table 4).

\section{Next Steps}

As we search for better answers for solving today's challenging environment issues, we need to have the proper data and analysis systems in place. LCA offers a structured methodology for looking at the issues, and quality LCI data provide the starting point for the analysis. We are committed to making the U.S. LCI Database a leader in quality, completeness, and transparency. This roadmap provides a path toward that vision. It will take a continued effort and attention to detail, but the result will be better information for improved environmental decision making.

NREL and DOE will work with their partners to implement the steps laid out in this roadmap. Along the way, we will keep the project open and flexible to work with the changing environment and handle unforeseen challenges.

\section{Table 4. Long-Term Objectives}

\section{Project Management}

Maintain a viable project business plan.

Develop and sustain project partnerships.

Maintain business and technical advisory boards.

Support expanding use of LCA.

Coordinate with national and international LCA/LCI efforts.

Data Management

Periodically review data formats and protocols.

Maintain a data reviewer qualification plan.

Sustain a data quality review program.

Expansion/Revision of the Database

Periodically review and update or replace data sets.

Incorporate new data from current LCA efforts.

Develop new LCl data sets.

Communications

Implement a users' forum.

Develop educational materials.

Maintain the project Web site. 


\section{Acknowledgments}

This project has been and continues to be the product of dedicated and creative individuals. Not everyone can be mentioned here, but the following individuals deserve special recognition for their efforts. Drury Crawley from the Buildings Technology Program at DOE had the foresight to understand the need and the willingness to initiate and continue support for the project. Wayne Trusty and the Athena Institute have provided the vision, expertise, and tireless work to bring everyone and everything together to make it a reality. Rita Schenck from the Institute for Environmental Research and Education and the American Center for Life Cycle Assessment has worked persistently to inject renewed interest and keep this project moving. Greg Norris of Sylvatica and Bill Franklin, Bev Sauer, Bob Hunt, and James Littlefield of Franklin Associates provided their LCA expertise and hard work to help develop and guide the implementation of the database. Steven Janzou provided all the database and data format programming. Pascal Lesage of Sylvatica meticulously reviewed the entire database and provided consistency throughout the data. In addition, the following individuals have provided their expertise to keep this project moving in the right direction: Mike Levy of the American Chemistry Council, Lise Laurin of the Earthshift, Nuno da Silva of PE Americas, Mark Goedkoop of PRé Consultants, Martha Stevenson of GreenBlue, Jeff Rice of the University of Arkansas, Neil Huizenga of Microsoft, Thomas Gloria of LifeCycle Services LLC, and Jon Dettling of EcoIntesys.
The following organizations have contributed to the U.S. LCI Database project with funding, labor, or LCI data.

\section{Contributors to the U.S. LCI Database Project}

U.S. Department of Energy

U.S. General Services Administration

U.S. Environmental Protection Agency

U.S. Forest Service

National Institute of Standards and Technology

U.S. Navy

U.S. Green Building Council

CORRIM

Vehicle Recycling Partnership of USCAR

Athena Institute

Franklin Associates

Sylvatica

Institute for Environmental Research and Education American Chemistry Council

Portland Cement Association 
Representatives from the following organizations participated in the stakeholders' roadmap meeting held in Washington, D.C., on February 18, 2009.

\section{Participating Organizations in Stakeholder's Meeting}

The Aluminum Association

American Chemistry Council

American Institute of Steel Construction

Argonne National Laboratory

Athena Institute

BD Medical

Black \& Veatch

The Carbon Trust

Concurrent Technologies Corporation

Decra Roofing Systems

Earthshift

Ecointesys

Five Winds International

Franklin Associates

Green Building Alliance

Green Seal

GreenBlue

Institute for Environmental Research and Education

Metal Building Manufacturers Associations

Metal Construction Association
National Association of Home Builders

National Center for Manufacturing Sciences

National Institute of Standards and Technology

National Renewable Energy Laboratory

National Trust for Historic Preservation

Navarro Research \& Engineering

North American Insulation Manufacturers

Association

PE Americas

Shaw, Inc.

Steel Recycling Institute

Sylvatica

U.S. Department of Agriculture, Forest Service R\&D

U.S. Department of Energy

U.S. Environmental Protection Agency

U.S. General Services Administration

U.S. Green Building Council

University of Arkansas

University of California, Santa Barbara

Michael Deru, Ph.D.

U.S. LCI Database Project Manager

National Renewable Energy Laboratory 


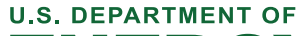 ENERGY}

Energy Efficiency \& Renewable Energy
Prepared by the National Renewable Energy Laboratory (NREL) NREL is a national laboratory of the U.S. Department of Energy Office of Energy Efficiency and Renewable Energy Operated by the Alliance for Sustainable Energy, LLC
For more information contact: EERE Information Center

1-877-EERE-INF (1-877-337-3463)

www.eere.energy.gov/informationcenter

Printed with a renewable-source ink on paper containing at least $50 \%$ wastepaper, including $10 \%$ post consumer waste. 